\title{
Inventário e patrimônio cultural no Brasil
}

Antonio Gilberto Ramos Nogueira *

\section{Resumo:}

A desmaterialização do patrimônio cultural recolocou a necessidade dos inventários como instrumentos de reconhecimento da diversidade cultural e ponto de partida para as políticas públicas de patrimônio. Assim, refazer a trajetória de Mário de Andrade na constituição do Inventário dos Sentidos é buscar as origens da formulação de uma noção de patrimônio e de uma concepção de preservação que coloque o inventário no centro da prática preservacionista (principalmente quando se trata de patrimônio não tangível) legitimando-o como instrumento de preservação em si e não apenas como ferramenta de gestão para bens já tombados. Signo das narrativas modernistas de construção da brasilidade, está em sua gênese, articulada às "viagens de (re)descoberta do Brasil" (1924, 1927 e 1928\1929) e posteriormente objetivada nas ações do Departamento de Cultura de São Paulo (1935-1938).

Palavras-chave: patrimônio cultural, inventário, multimeios, cultura popular, memória coletiva

Se hoje vivemos no Brasil um revigoramento do patrimônio cultural, principalmente depois que o Decreto 3.551, de 4 de agosto de 2000, instituiu o Registro e o Inventário do Patrimônio Cultural de natureza imaterial ou intangível, é porque a semente de uma noção de patrimônio ampla e plural que procurava abarcar todas as manifestações do povo brasileiro foi plantada e gestada por Mário de Andrade, sobretudo na experiência do Departamento de Cultura (1935-1938). Imortalizada no conceito de arte patrimonial que o poeta elaborou no Anteprojeto para criação do Serviço do Patrimônio Artístico Nacional, em 1936, é vetor de sua consciência da diversidade da cultura brasileira.

Os sentidos amplos e diversificados dado à palavra arte - "habilidade com que o engenho humano se utiliza da ciência, das coisas e dos fatos” (Andrade, 1981, p.44) revelam uma idéia de patrimônio cultural que se expressa tanto em sua forma material quanto em sua forma imaterial ou intangível. Ou seja, é um sentido amplo de cultura que opera a noção de arte patrimonial, daí que a distinção entre o que é material e imaterial não cabe em uma concepção que tem como foco o conhecimento e o processo criativo. 
De nítida orientação etnográfica, pode-se igualmente vislumbrar uma perspectiva antropofágica de cultura, tendo em vista a preocupação de Mário em apreender os processos de constituição e reinvenção dos elementos que compõem a memória coletiva informadores de nossas matrizes européias, africanas e ameríndias. Nas oito categorias de arte que fundamentam sua concepção de patrimônio, incluía, entre arte arqueológica e a arte ameríndia, os fetiches, instrumentos de caça, de pesca, de agricultura, indumentárias, vocabulário, cantos, lendas, magias e culinária. Entre as manifestações da arte popular definia os fetiches, cerâmica em geral, indumentárias, arquitetura popular, cruzeiros, capelas e cruzes mortuárias de beira-de-estrada, jardins, paisagens, música popular, contos, histórias, lendas, superstições, medicina, receitas culinárias, provérbios, ditos, danças dramáticas.

Explícito também era o papel do inventário e o registro, por meio dos multimeios, de tais manifestações: “a fonografia gravando uma canção popular cientificamente ou filme sonoro gravando tal versão baiana do bumba-meu-boi, impedem a perda destas criações que o progresso, o rádio, o cinema estão matando com violenta rapidez” (ibidem, p.53).

Muito diferente da idéia de patrimônio que vigorou até recentemente, representada quase que exclusivamente pela "sacralização da memória em pedra e cal” (Nogueira, 1995). Pautada no valor de excepcionalidade, privilegiou um repertório de bens cujas expressões culturais hegemônicas conformavam uma tradição européia luso-brasileira - geralmente identificada com o poder constituído. Seguindo essa orientação também a prática preservacionista ficou praticamente reduzida ao tombamento, sendo a restauração e a conservação seus correlatos.

Embora rejeitado, o projeto andradiano para o patrimônio cultural será retomado, em partes, por Aloísio Magalhães, na criação do Centro Nacional de Referência Cultural (posteriormente Fundação Nacional Pró-Memória), nos idos de 1970. Partindo da proposta de proceder ao "referenciamento da dinâmica cultural brasileira”, vários inventários foram realizados com o propósito de catalisar a idéia de um “patrimônio cultural não consagrado”, consubstanciado na reelaboração da noção de cultura popular (Magalhães, 1985; Fonseca 1997, p.147-204; 1998). Paralelamente a essa iniciativa, não se pode olvidar das experiências empreendidas por folcloristas e antropólogos, do início do século XX, no registro do popular. A título de exemplo cabe lembrar a criação da Comissão Nacional de Folclore, a partir do final da década de 1940. Quarenta anos mais tarde, numa perspectiva notadamente antropológica, veio a 
ser incorporada no âmbito da Funarte pelo Instituto Nacional do Folclore (hoje Centro Nacional do Folclore e Cultura Popular).

Isto posto, esse novo momento que a área do patrimônio cultural está vivendo é uma rara oportunidade para discutir a importância e a necessidade dos inventários como instrumentos de reconhecimento da diversidade cultural e ponto de partida para as políticas públicas de patrimônio. Assim, refazer a trajetória de Mário de Andrade na constituição do Inventário dos Sentidos (Nogueira, 2005) é buscar as origens da formulação de uma noção de patrimônio e de uma concepção de preservação que coloque o inventário no centro da prática preservacionista (principalmente quando se trata de patrimônio não tangível), legitimando-o como instrumento de preservação em si e não apenas como ferramenta de gestão para bens já tombados. Signo das narrativas modernistas de construção da brasilidade, está em sua gênese, articulada às "viagens de (re)descoberta do Brasil” (1924, 1927 e 1928\1929) e posteriormente objetivada nas ações do Departamento de Cultura de São Paulo (1935-!938).

Refletir sobre o legado do Departamento de Cultura é colocar, no centro e ao lado do debate sobre a herança maior que é a Política Cultural da cidade de São Paulo, o caráter pedagógico do Departamento. Paradigma deixado por Mário de Andrade: “Educação totalizadora de sua gente”. Também a construção de uma identidade nacional e de um acervo de brasilidade eram as metas do poeta de Paulicéia Desvairada quando esteve na direção do Departamento. Sob esse olhar, a experiência do Departamento se confunde com a própria trajetória multifacetada do modernista - uma obsessiva tarefa de inventariar e registrar os elementos constituidores da cultura brasileira.

Aqui a idéia é apresentar o quanto a preocupação do pai de Macunaíma com a cultura popular e o folclore, em consonância com a sua missão de conhecer e revelar o Brasil, se traduziu na pedagogia do Departamento materializada na Missão de Pesquisas Folclóricas. Mário de Andrade e o Inventário dos Sentidos serão fio condutor.

\section{Viagens de (re)descoberta do Brasil: repertório para o patrimônio imaterial}

Antes mesmo da emblemática "Viagem de Descoberta do Brasil”, de 1924, a Minas Gerais, o despertar de Mário para o patrimônio pode ser identificado em outras duas viagens: Minas Gerais (1919) e Itanhaém, litoral sul de São Paulo (1921). Em 
busca da tradição o poeta vai ao encontro do passado arquitetônico colonial. Do itinerário dessa primeira viagem, sobressai o desejo de Mário de conhecer o poeta simbolista Alphonsus Guimarães e observar, in loco, a herança colonial do ciclo do ouro.

Deslumbrado com a riqueza da arte colonial religiosa (arquitetura, imaginária e pintura), logo declarou sua missão: “É um fóssil, necessitando ainda de classificação, de que pouca gente ouviu falar e ninguém incomoda” (Andrade 1993). Vislumbrando a importância do barroco como motivo de inspiração para a futura arte nacional, escreve Arte Religiosa do Brasil, série de quatro crônicas publicadas na Revista do Brasil, em 1920. Aí todo o patrimônio de Ouro Preto, Mariana, São João Del Rei e Congonhas do Campo ficou registrado no ensaio dedicado ao barroco mineiro.

A viagem de 1924, às Minas Gerais, é, sob muitos aspectos, o divisor de águas das narrativas modernistas. Coincide com ou possibilita colocar na agenda dos membros da “caravana paulista” - composta por Mário de Andrade, Oswald de Andrade, Tarsila do Amaral, D. Olívia Guedes Penteado, Paulo Prado, entre outros, quando da chegada do poeta Blaise Cendrars - a questão da brasilidade. Do encantamento com a "grandeza antiga dormindo sono de cobra” (Andrade in Batista et al., 1984, p.111-112) os descobridores tomaram consciência da alienação vivida pela cultura brasileira e a certeza de que a construção de uma arte e uma cultura nacionais passavam pelo resgate do passado como referencial. Das lições de Aleijadinho e mestre Ataíde, por exemplo, está o despertar dos membros da caravana para o patrimônio e igualmente a tomada de consciência para as problemáticas da preservação e sua institucionalização. É da necessidade de uma revisão do acervo tradicional que podemos encontrar nas problemáticas modernistas a preocupação com o patrimônio cultural.

Já em carta de1926, ao amigo Câmara Cascudo, Mário confessava:

\footnotetext{
Tem momentos em que eu tenho fome, mas positivamente física, fome estomacal de Brasil agora. Até que enfim sinto que é dele que me alimento! Ah! si eu pudesse nem carecia você me convidar, já faz sentido que tinha ido por essas bandas do norte visitar vocês e o norte. Por enquanto é uma pressa tal de sentimentos em mim que não espero nem seleciono. Queria ver tudo, coisas e homens bons, ruins, excepcionais e vulgares. Queria ver, sentir, cheirar. Amar já amo. (Andrade, 1991, p. 35)
}

Foi com esse objetivo que o Mário-viajante empreendeu suas viagens de Turista Aprendiz pelo Norte e Nordeste brasileiros. Revelar o Brasil, caracterizá-lo física e simbolicamente é estar lá, ver, ouvir, sentir, tocar, cheirar, degustar, também, registrar, 
catalogar, expor. Nesse itinerário de descobertas o corpo serve como passagem na mediação com o tempo e o espaço do norte, aqui também das origens e da tradição. Rumo ao norte, o Mário-pesquisador vai ao encontro do popular, elemento constitutivo de uma estética e identidade nacionais.

As Viagens Etnográficas, como ficaram conhecidas, são reveladoras de momentos privilegiados em que podemos identificar no desejo do estudioso da cultura popular de coletar diretamente da fala do povo a brasilidade procurada (respeitando a composição popular em sua linguagem e estrutura) a intenção de posteriormente cruzar tais informações com a pesquisa bibliográfica, garantindo foro de cientificidade. Objetivava em seus planos escrever uma grande obra do folclore musical brasileiro intitulada Na Pancada do Ganzá. É também um momento de transição entre uma perspectiva literária e musical para uma abordagem mais conceitual de cultura.

No diário do Turista Aprendiz é notória a configuração de uma metodologia de registro do patrimônio cultural expresso, tanto em sua forma material como imaterial. Pode-se até mesmo sugerir que aí se encontra um repertório do que hoje se convencionou a chamar de patrimônio imaterial. Assim, ao lado das igrejas, pontes e chafarizes, registrou os sabores e cores do Brasil: sorvetes coloridos de Belém, sucos, culinária; tipos brasileiros (a semostração da carioca, a beleza dos índios e dos mestiços, a fala cantada e a verve cômica do nordestino); as danças dramáticas; as melodias de boi; música de feitiçaria; religiosidade popular, crenças, superstições; poesia popular (cordel); formas de expressão; instrumentos musicais; modos de trabalhar, modos de morar, modos de festejar, etc.

Durante a segunda viagem, que ocorreu entre 1928 e 1929 e que passa pelo Rio Grande do Norte, Paraíba e Recife, o Mário-músico é o “dotô de São Paulo que veio studa boi”, nos trabalhos que realizou no Rio Grande do Norte, Natal e arredores. Nos ensaios da Chegança e Pastoril que se preparavam para o Natal observa:

Todas as danças dramáticas inda permanecidas tão vivas na parte norte e nordeste do país, andam muito misturadas, umas trazem elementos de outras, influências novas penetradas nelas, junto duma lição camoniana brota um brasileirismo danado, contando fatos de agora, tão impossíveis que a Turquia chega a conhecer a força do 'braço brasileiro' na presença do imperador Guilherme II.

Em outra passagem conclui:

A dança é longa demais. Um esforço muscular que dura três, quatro horas. Me retiro tonto de comoção quando o coro conta que quem venceu definitivamente os mouros foi o duque de Caxias. (Andrade, 1983, p.236 e 247) 
Testemunhos da antropofagia do povo brasileiro, processo de absorção de influências que se diluem e se recompõem na reinvenção das tradições acrescidas de novas estruturas e outras combinações rítmicas e melódicas; traduzem musicalmente o sentido popular dado à contemporaneidade. São evidências que apontam na direção da elaboração do conceito de tradições móveis, elemento fulcral na operação da noção de uma temporalidade brasileira.

Todavia, se é no registro de Cocos e de melodias de boi que se delineia a preocupação de Mário em apreender o processo criativo e a revitalização da memória coletiva, aí se encontram as pistas em que denuncia a necessidade de aparelhos especiais para não se perder nenhum detalhe. Embora o dedo do pesquisador não cansasse de disparar sua kodaquinha na tentativa de capturar todos os detalhes (já que para ele a fotografia era considera uma importante aliada na preservação da tradição), era da falta do fonógrafo a que se referia acima ao falar de tais aparelhos especiais.

\section{Departamento de Cultura e a constituição de um acervo de brasilidade}

Nessa visada, a concepção ampla de patrimônio e a preocupação com o registro e preservação desse patrimônio orientam e refletem as ações educativas do Departamento de Cultura. No limite, pode-se dizer que o caráter pedagógico pautado nos "sistemas de cultura geral" com o objetivo de "facilitar, alargar e aprofundar a educação totalizadora de sua gente" ${ }^{2}$ tem nos esportes, na socialização da criança, na higiene, nas bibliotecas, nas artes e sobretudo na conservação das tradições seu foco principal. Assim podem ser vistos os projetos para a Divisão de Bibliotecas, a Divisão de Educação e Recreio e principalmente a Discoteca Pública. A educação infantil e a recreação são vistas como necessárias no processo de resgate e reinvenção de práticas culturais populares que estavam se perdendo no amálgama cultural da cidade de São Paulo. A partir das festas e brincadeiras tradicionais, a criança e principalmente os filhos dos operários imigrantes poderiam ser incorporados no projeto nacional do Departamento.

Já a Discoteca seria o repositório da cultura, lugar de memória nacional. A partir dos trabalhos com o folclore, etnografia e cultura popular, Mário dispõe os serviços da Discoteca à realização do seu Inventário dos Sentidos. Pensada como centro de documentação e lugar de difusão das manifestações populares, o objetivo era solucionar 
o amadorismo da coleta e do registro das expressões da cultura popular. Mário de Andrade, à semelhança de Amadeu Amaral e Silvio Romero, criticava a formação precária dos pesquisadores como a responsável pelo amadorismo dos estudos folclóricos. Em entrevista ao Jornal Síntese (1936), o então diretor do Departamento de Cultura declarou:

\begin{abstract}
A etnografia brasileira vai mal. Faz-se necessário que ela tome imediatamente uma orientação prática baseada em normas severamente científicas. Nós não precisamos de teóricos, os teóricos virão a seu tempo. Nós precisamos de moços pesquisadores, que vão à casa do povo recolher com seriedade e de maneira completa o que esse povo guarda e rapidamente esquece, desnorteado pelo progresso invasor. (Andrade, 1936)
\end{abstract}

Nessa movida, além de dotar a Discoteca de equipamentos modernos para o registro sonoro (gravador Presto Recorder), fotográfico (câmara Rolleiflex) e fílmico (Kodak), promove, sob a mediação da USP, o Curso de Etnografia e Folclore ministrado por Dina Levi-Strauss. Das aulas ministradas por Dina Levi-Strauss é nítida a definição do papel da etnografia para o projeto em curso. Segundo a autora, a etnografia como uma ciência essencialmente descritiva e monográfica é a que melhor possui um “método geral de investigação”, para se estudar os “outros” que compõem a pluralidade da cultura brasileira. Recomenda ainda a necessidade de estudos etnográficos não só para o Brasil, mas para toda a América do Sul (Sociedade..., doc. 8).

Também a orientação para o uso dos multimeios como suporte e recurso metodológico na pesquisa etnográfica vinha confirmar tudo aquilo que Mário havia idealizando desde suas viagens etnográficas. A fotografia é a arma essencial na produção de evidências que procuram apreender o outro. Nesta perspectiva, ela é o objeto (fragmento e vestígio do real) e sua descrição. Já o cinema é fundamental para o registro do elemento performático (tradições, gestos, danças, sons e falas). Na sistematização da coleta musical a proposta era aliar o registro mecânico (fonógrafo e filme sonoro) ao registro não mecânico (anotação direta) (idem).

Trata-se de um momento emblemático do deslocamento de uma abordagem literário-musical para um novo empreendimento folclore-etnografia que, aliado à institucionalização permitida pela criação da Sociedade de Etnografia e Folclore, confere cientificidade a uma série de atividades voltadas para o inventário, o registro e a preservação da diversidade das manifestações populares. Igualmente a abertura da Seção “Arquivo etnográfico” (Revista..., 1936, v.30) na Revista do Arquivo Municipal caminha nesta direção. As instruções para as pesquisas de campo sugerem a 
configuração de uma concepção de cultura próxima à antropologia norte-americana, especialmente aquela de Boas, Redfield, Herskovit, etc. Conclusivas, certamente, foi a incorporação de temáticas como cultura material e vida social.

Estimulados por essa ambiência, Mário e Oneyda Alvarenga, enquanto encaminhavam os preparativos para a realização da Missão de Pesquisas Folclóricas, recolhiam os primeiros registros que a Discoteca fizera no estado de São Paulo, Minas Gerais, Mato Grosso e Bahia. Passada as últimas instruções metodológicas, definido o roteiro e priorizadas as manifestações folclóricas, a escolha dos componentes da Missão levou em consideração a aplicabilidade da metodologia e o sucesso do empreendimento diante da ausência de seu mentor. Foram escolhidos Luís Saia - chefe da expedição, arquiteto e engenheiro, era amigo de Mário, foi aluno de Dina Levi-Strauss e sóciofundador da SEF; Martin Braunwieser - músico; Benedito Pacheco - técnico de som e Antonio Ladeira - auxiliar geral e assistente técnico de gravação.

Se o Departamento de Cultura foi a vida e morte de Mário de Andrade como aludiu Paulo Duarte, a Missão de Pesquisas Folclóricas era, sem dúvida, sua grande paixão. Entre as cartas de apresentação e recomendação aos amigos modernistas/folcloristas um bilhete seu, de 22 de janeiro de 1938, comprova a importância desse trabalho na materialização do Inventário dos Sentidos:

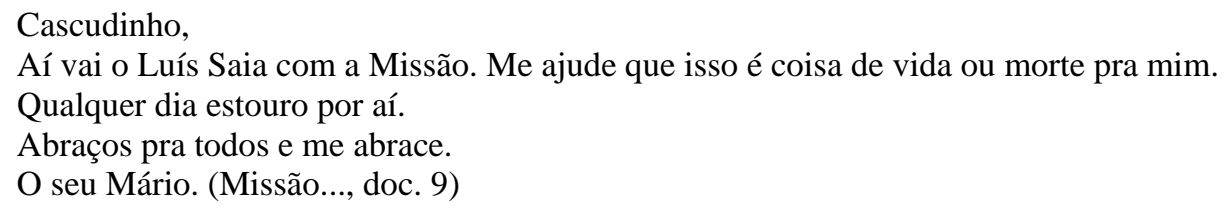

No dia 6 de fevereiro de 1938, o vapor Itapajé partiu do porto de Santos com destino ao Recife (PE) levando uma "grande e poderosa expedição”, a julgar pelo volume das bagagens. Seis malas e três caixas abrigavam o gravador Presto Recorder, amplificador, 50 caixas de agulhas para a reprodução, microfones com cabos e tripé, válvulas, 237 discos, gerador, aspirador de pó, blocos de papel, 118 filmes fotográficos, 21 filmes cinematográficos, câmara fotográfica Rolleiflex com filtros e lentes, aparelho cinematográfico Kodak, também com filtros e lentes e pastas de couro para guardar os discos.

Depois de passagens rápidas pelo Rio de Janeiro, Vitória, Salvador e Maceió, a Missão aportou em Recife, no dia 13 de fevereiro, permanecendo em Pernambuco até 23 de março. O clima tenso e a vigilância da polícia obrigaram o chefe da Missão a 
sacar uma espécie de plano B, sendo forçado a entrar em contato com o mundo oficial de Pernambuco. Alguns contatos de Mário, a exemplo de Gilberto Freyre, foram considerados perseguidos pelo regime do Estado Novo, como perseguidos também estavam os cultos de xangô. Com a proibição de tais práticas religiosas e o fechamento dos terreiros, coube a Ascenso Ferreira e Valdemar de Oliveira fazerem a mediação com a polícia local para conseguirem algum registro.

Os relatórios e as cartas que Saia fez chegar até Mário e aos sócios da Sociedade de Etnografia e Folclore, mais as matérias publicadas nos jornais locais, são ricas informações que nos ajudam a reconstruir esse cotidiano da Missão. Os primeiros trabalhos aconteceram no bairro de Paulista, onde assistiram a um ensaio de Maracatu. Já no teatro Santa Izabel, gravaram canto de carregadores de piano, toadas de bumbameu-boi e registraram o grupo de xangô da Guida. Nos municípios de Rio Branco Tacaratu, Brejo dos Padres e Folha Branca registraram cocos (embolada, martelo e roda), cantigas de roda, sertaneja, pedintes, coletaram milagres (ex-voto), filmaram cabocolinhos, maracatus e principalmente o toré dos índios pancarus e a sua festa do umbu.

No estado da Paraíba, com um clima político mais favorável, a Missão permaneceu até 30 de maio, fazendo coleta nos arredores de João Pessoa e sertão adentro. Com destino a Cajazeiras, percorreram Patos, Pombal, Souza, Curema e arredores filmando e fotografando bumba-meu-boi, aspectos da vaquejada, reis do congo; gravaram cocos, abios, cantigas infantis, sambas, canto de pedintes, canto de carregadores de pedra, reisados, modas, desafios, repentes, lundus, cabaçal, nau catarineta, catimbó e também registraram poética e arquitetura populares, manufaturas de violas, etc. Antes de partirem ainda registraram os cabocolinhos tupi-guaranis, o catimbó de Luís Gonzaga Ângelo e a Barca de João Pessoa.

Na terceira etapa da viagem cujo objetivo era passar pelo Maranhão e chegar até o Norte para as festas juninas, a Missão entra numa espécie de desajuste. Diante da complicada situação política e principalmente da substituição de Mário por Francisco Pati, na chefia do Departamento, Saia opta por um trajeto terrestre visando a uma maior dificuldade de comunicação com a equipe. Na iminência de a Missão ser abortada antes de se chegar ao destino final, empreendem uma longa viagem de dezessete dias, percorrendo de caminhão o sul do Ceará, via Crato, e o Piauí até chegar a São Luís. 
Pobre em registros etnográficos, a riqueza dessa etapa da viagem ficou por conta das anotações particulares feitas por Saia em seu diário.

Entre os dias 15 e 21 de junho, os trabalhos concentraram-se na capital do Maranhão, onde o interesse imediato eram os cultos fetichistas: Tambor de criolo e Tambor de mina. Ali também registraram bumba-meu-boi e carimbó. Em Belém do Pará permaneceram até 7 de julho, quando foram obrigados a retornar a São Paulo. Sob a mediação de Gastão Vieira, amigo pessoal de Mário, conseguiram registrar em fotos, discos, filmes e anotações diretas o bumba-meu-boi do grupo Boi Bumbá "Pai do Campo”, melodias de pajelança e o culto de feitiçaria babaçuê do mestre Sátiro Ferreira de Barros.

Dos lugares de memória, a Missão trouxe o Brasil na mala. Pelo registro etnográfico, o patrimônio não tangível chegou à Discoteca Pública Municipal de São Paulo, constituindo um lugar de memória nacional. São pedaços do Brasil: lugares, festas, músicas, danças, falas, costumes, religiosidades, gestos, saberes, saber-fazer, manifestações de vida descobertas e materializadas em 1.066 fotos, nove rolos de filme, 168 discos 78 RPM, 770 objetos e vinte cadernetas de campo. Todo esse material será cuidadosamente sistematizado por Oneyda Alvarenga e parte divulgada na coleção Arquivo Folclórico (v.I: Melodias registradas por meios não mecânicos, 1946, e v.II: Catálogo ilustrado do Museu do Folclore, 1948) e na coleção Registros sonoros de folclore musical brasileiro (RSFMB), concebida para auxiliar a audição dos discos masterizados (v I.: Xangô, 1948; v.II: Tambor de Mina e Tambor de Crioulo, 1948; v.III: Catimbó, 1949; v.IV: Babaçuê, 1950; e v.V: Cheganças de Marujo, 1956).

A intenção de disponibilizar esse acervo para consulta, como idealizou Mário em seu projeto de educação patrimonial, foi sendo realizada lentamente pelo poder público. É o caso da exposição permanente Cantos Populares do Brasil: A Missão de Mário de Andrade, que o grande público teve acesso a partir de 2004; o lançamento da caixa com 6 CDs da Missão de Pesquisas Folclóricas, que a parceria da Secretaria Municipal da Cultura com o Sesc São Paulo concretizou, em 22 de agosto de 2006; e o próprio reconhecimento do Iphan que, somente em agosto de 2005, aprovou o tombamento do material audiovisual referente ao acervo histórico da Discoteca Oneyda Alvarenga.

Assim, refletir sobre a concepção de patrimônio imaterial e sua política de preservação como fruto dessa experiência do Departamento de Cultura no registro do popular é fazer jus ao pioneirismo de Mário na constituição de uma política cultural 
voltada para o patrimônio e igualmente pioneira no sentido de utilizar o registro multimeios (fotografias, filmes e registros sonoros) para sua preservação e promoção.

\section{REFERÊNCIAS BILIOGRÁFICAS:}

ANDRADE, M. In: Recortes Mário de Andrade, pasta (1921, 1926, 1936). Jornal Síntese. Belo Horizonte, 1936. Arquivo Mário de Andrade. São Paulo: IEB\USP.

Mário de Andrade: Cartas de trabalho: correspondência com Rodrigo Melo Franco de Andrade (1936-1945). (Introdução e Notas Lélia Coelho Frota) Brasília: MECISPHAN\FNPM, 1981.

O Turista Aprendiz. (Estabelecimento de Texto, Introdução e Notas de Telê Porto Ancona Lopes) São Paulo: Duas Cidades, 1983.

. In: Batista, M. R. et al. Brasil: 10 tempo modernista - 1917\29 (Documentação). São Paulo: IEB\USP, 1984.

A arte religiosa no Brasil. São Paulo: Experimento, 1993.

FONSECA, Maria Cecília Londres. O patrimônio em processo: trajetória federal de preservação no Brasil. Rio de Janeiro: UFRJ $\backslash$ Minc-IPHAN, 1997.

A noção de referência cultural nos trabalhos de Inventário. In: Inventário de Identificação um panorama da experiência brasileira. Rio de Janeiro: UFRJ\MincIPHAN, 1998.

MAGALHÃES, Aloísio. E triunfo? A questão dos bens culturais no Brasil. Rio de Janeiro: Nova Fronteira\Fundação Nacional Pró-Memória, 1985.

MISSÃO de Pesquisas Folclóricas (Doc. 9). Arquivo Histórico da Discoteca Oneyda Alvarenga. Centro Cultural São Paulo.

NOGUEIRA, Antonio Gilberto R. O SPHAN e a Redescoberta do Brasil: a sacralização da memória em pedra e cal. PUC-SP: Dissertação de Mestrado, 1995.

Por um inventário dos sentidos: Mário de Andrade e a concepção de patrimônio e inventário (Prêmio Silvio Romero 2004). São Paulo: HucitecłFapesp, 2005.

REVISTA do Arquivo Municipal, 1936. v.30.

SOCIEDADE de Etnografia e Folclore (Doc. 8). Acervo Histórico da Discoteca Oneyda Alvarenga. Centro Cultural São Paulo. 
NOGUEIRA, Antonio Gilberto Ramos. Inventory and cultural patrimony in the Brazil. História, São Paulo, v. 26, n. 2, p. 257-268, 2007.

\begin{abstract}
The dematerialization of cultural patrimony has brought back the necessity of inventories as tools for the recognition of cultural diversity and the starting point for public policies of patrimony. Thus, retracing the trajectory of Mario de Andrade in the constitution of the Inventory of the Senses means searching for the origins of the formulation of a notion of patrimony and of a conception of preservation which puts the inventory in the center of a preservation practice (especially with regards to non-tangible patrimony) legitimizing it as a tool for preservation itself and not only as a managing tool for assets already registered. Signal of the modernist narrative of the construction of a "Brazilianness", it is in its genesis, articulated to the "rediscovery travels to Brazil (1924, 1927, and 1928/1929) and, later on, objectified in the actions of the Culture Bureau of São Paulo (1935-1938).
\end{abstract}

Keywords: cultural patrimony, inventory, multimedia, popular culture, collective memory.

Artigo recebido em 07/2007. Aprovado em 11/2007.

\title{
NOTAS:
}

\footnotetext{
* Professor do Departamento de História da UFC.

${ }^{1}$ Durante o longo percurso da primeira viagem (Viagem pelo Amazonas até o Peru, pelo Madeira até a Bolívia e por Marajó até dizer chega), Mário ia registrando suas impressões e observações da vida do povo num diário que deveria se transformar num "livro de viagens": O Turista Aprendiz. No retorno, grande parte desse material foi explorada em forma de crônicas, publicadas no recém-fundado Diário Nacional. Na segunda viagem (Alagoas, Rio Grande do Norte, Paraíba e Pernambuco), na condição de correspondente do Diário Nacional, vai transformando automaticamente os seus apontamentos em crônicas da série $O$ Turista Aprendiz.

${ }^{2}$ Processos Administrativos do Departamento de Cultura (1935-1938), n. 75259. Arquivo Municipal Washington Luís.
} 